\title{
TWO-STAGE METHOD OF CATHODE ELECTROLYTE-PLASMA HEATING FOR CHEMICOTHERMAL TREATMENT OF METAL MATERIALS
}

\author{
RAKHADILOV B.K. ${ }^{1,2}$, SATBAYEVA Z.A. ${ }^{1,2}$, BAYZHAN D. ${ }^{1}$, KOZHANOVA R.S. ${ }^{1}$

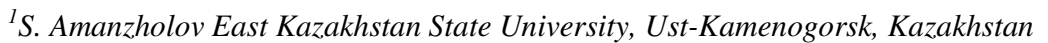 \\ ${ }^{2}$ LLP «PlasmaScience», Ust-Kamenogorsk, Kazakhstan
}

\begin{abstract}
This work presents the results of studies on the features of the cathode electrolyte-plasma process. There were studied the current-voltage characteristics of cathode electrolyte-plasma process of treatment. The experiments were carried out with electrolytes from an aqueous solution containing $10 \%$ sodium carbonate and 15, 20, $25 \%$ urea. The currentvoltage characteristics of the cathodic heating process were obtained in order to establish the possibility of controlling the electrolyte-plasma discharge and establish the boundaries of the working areas for PES.The current-voltage characteristics of the cathode process were obtained at various temperatures of the electrolyte and the active electrode (cathode). It was found that it is necessary either that the electrolyte be heated from $70{ }^{\circ} \mathrm{C}$ or the active electrode (cathode) is heated to $500{ }^{\circ} \mathrm{Cin}$ order to obtain a stable discharge at lower voltages. In order to obtain a stable discharge, the authors have developed an efficient two-stage cathodic heating mode, which allows for controlled cathodic plasma electrolytic saturation (PES) of steels.

The method of two-stage electrolyte-plasma heating is the heating of the active electrode (cathode) to 400-500 ${ }^{0} \mathrm{C}$ with an abnormal discharge at voltages of 300-320 V, followed by a transition to film boiling mode by a sharp decrease in voltage to 180-200 $\mathrm{V}$. The developed mode allows to obtain a stable discharge without the use of any additional operations on the same installation, which reduces the complexity of the process while increasing the productivity of the process.
\end{abstract}

KEYWORDS: Electrolyte-Plasma Process, Cathodic Heating, Current-Voltage Characteristics, Electrolyte

Received: Jun 08, 2020; Accepted: Jun 28, 2020; Published: Sep 22, 2020; Paper Id.: IJMPERDJUN20201380

\section{INTRODUCTION}

The electrolyte-plasma treatment method is one of the methods of high-speed heating where the treatment workpiece is a cathode or anode relative to an aqueous electrolyte [1]. It is possible to harden [2], plasma electrolytic oxidation (PEO) [3] and plasma electrolytic saturation (PES) [4, 5] of materials depending on the heating mode, electrolyte composition, design parameters of the equipment. PES is produced by heating and holding in a saturating medium due to a change in the electric potential in the plasma layer created between the electrolyte and the sample surface. Interstitial atoms, such as C, O, and N, diffuse onto the surface of metals, which leads to an improvement in their surface properties [6,7] during PES.PES is carried out at a potential exceeding the breakdown value of gas bubbles that can be operated under the conditions of the anode or cathode relative to the electrolyte bath [8-10]. There are many articles where anode PES has been studied [11-15], but there is a knowledge gap about the cathode PES process. The main reason for the limitation when using cathode PES is the instability of plasma formation between the liquid electrode and the surface of the product. Therefore, one of the 
important tasks in the field of PES is the development of a method and mode of cathodic heating of workpieces. In accordance with this, the present work describes the features of the cathode electrolyte-plasma process. The currentvoltage characteristics of the cathode electrolyte-plasma process are also compared depending on the temperature of the electrolyte and the cathode.

\section{EXPERIMENTAL}

The study of the CVC was carried out at the Scientific research center "Surface Engineering and Tribology" of S. Amanzholov East Kazakhstan State University on the UEPOM-M technological system [16, 17] (Figure 1). The installation consists of a chamber for electrolyte-plasma treatment of materials, a personal computer and a $40 \mathrm{~kW}$ power source. The chamber for electrolyte-plasma processing of materials is an electrolytic cell where is an anode and a coneshaped dielectric partition. The anode is made in the form of a perforated plate with a diameter of $120 \mathrm{~mm}$ from 12H18N9T steel.P6M5 steel was chosen as an active electrode (cathode) with a diameter of $22 \mathrm{~mm}$ and a length of $20 \mathrm{~mm}$. The immersion depth of the electrode in the electrolyte was 8-10 $\mathrm{mm}$. In the process, the electrolyte was in a circulating mode, and the feed rate of the electrolyte was $31 / \mathrm{min}$. The diameter of the opening of the conical septum was $20 \mathrm{~mm}$, which allowed creating a discharge only in the end surface of the electrode (cathode). The distance from the cathode surface to the hole was 3-5 $\mathrm{mm}$.
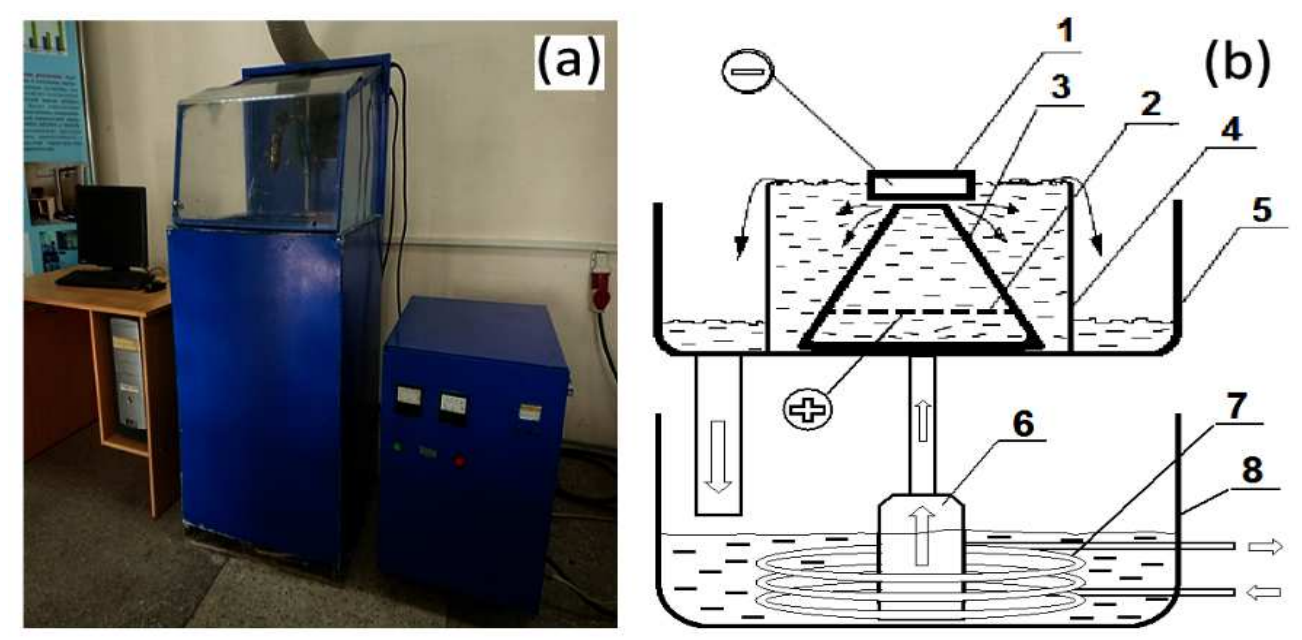

Figure 1: Overview (a) and scheme (b) of UEPOM-M EPT system: 1 - processed sample (cathode), 2 - stainless steel anode, 3 - cone-shaped partition, 4 - electrolytic cell, 5 - pallet, 6 - pump, 7 - heat exchanger, 8 - bath with electrolyte

The heating temperature of the studied sample (катод) was measured using a digital multimeter UNIT-33C and chromel-alumel thermocouple (accuracy $2 \%$ in range of 40 to $1000^{\circ} \mathrm{C}$ ). Thermocouple was inserted into a hole drilled in a cathode at a distance of $0,5 \mathrm{~mm}$ from heated surface. The layout of the thermocouple is shown in Figure 2.The temperature of the electrolyte in the bath was measured with a mercury thermometer. 


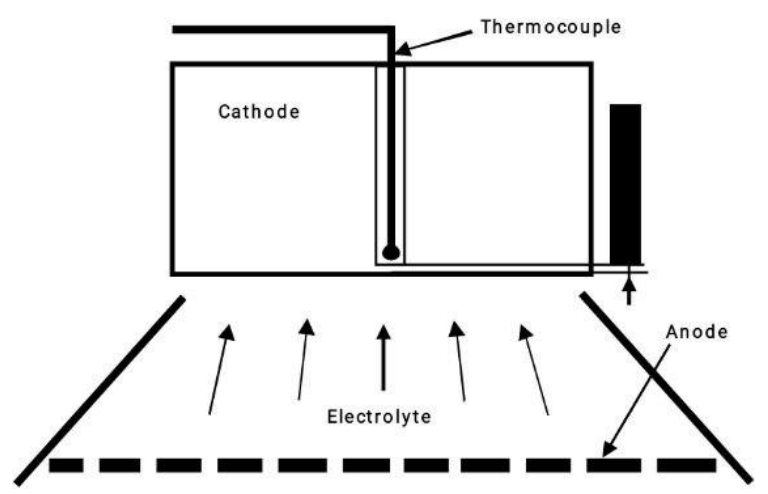

Figure 2: Scheme representing the position of the thermocouple in a sample during temperature measuring

The voltage at the electrodes and the average current strength between them were recorded in all experiments. The voltage varied stepwise with an interval of $10 \mathrm{~V}$ at constructing the I - V characteristic. The voltage was monitored by reaching the stationary readings of the ammeter for each value.

Experiments on the study of energy characteristics were carried out with electrolytes containing urea and sodium carbonate with various concentrations:

1) $15 \%$ urea, $10 \%$ sodium carbonate;

2) $20 \%$ urea, $10 \%$ sodium carbonate;

3) $25 \%$ urea, $10 \%$ sodium carbonate.

\section{RESULTS AND DISCUSSIONS}

Figure 3 presents the current-voltage characteristics of the cathodic electrolyte-plasma heating process at different concentrations of urea in the electrolyte. It can be seen that the current density value for all electrolyte concentrations at the same voltage values has approximately the same value, i.e. the magnitude of the current in this range does not greatly depend on the concentration of the electrolyte. Four areas can be traced in view of the current-voltage characteristics in electrolytes and visual observation at the cathode region.

The first area extends to voltages of $200-220 \mathrm{~V}$ in which the magnitude of the current is proportional to the applied voltage. A proportional increase in current strength with increasing voltage is characteristic for this section. This increases the temperature of the electrolyte, which is a consequence of the passage of current through the electrolyte. The temperature of the electrode and electrolyte in this area is lower than the boiling temperature of the electrolyte. This is an area where temperature gradients are negligible and heat is transferred by natural convection to the free surface of the liquid.

The electrolyte begins to boil and there is an active release of bubbles at the surface (bubble boiling) when a further increase in voltage on the surface of the active electrode (cathode). A slower increase in current is observed up to the maximum value. This is the second area of the characteristic at which the temperature of the active electrode reaches the boiling point of water $\left(100-110^{\circ} \mathrm{C}\right)$.

A sharp decrease in the current strength occurs at constant electrode and electrolyte temperatures at the end of this area $(230-250 \mathrm{~V})$. The third area sets in which characterized by instability of the system associated with rapid boiling of the electrolyte and individual discharges at different points of the active electrode. At the same time, a gas-vapor jacket 
with a thickness of about 50-120 $\mu \mathrm{m}$ [18] is created near the surface of the active electrode, isolating the active electrode from the electrolyte. The third area is characterized by the disappearance of bubble boiling and a sharp drop in current strength, due to the fact that the resulting gas-vapor shell has a greater electrical resistance than liquid electrolyte.Film boiling is observed. Since the gas-steam jacket is less electrically conductive, so the main voltage drop occurs precisely in this zone, where more heat is released. A low-temperature plasma is formed due to the formation of a gas-vapor jacket and the passage of electric current through it, which has a characteristic blue color of the glow of the shell around the part. The brighter the blue color of the plasma burning, the more it contains electrolyte ions, and, accordingly, nitrogen ions [19].

The formation of an abnormal discharge is observed with a further increase in voltage to 320-330 V, which leads to a more rapid increase in current strength and a sharp increase in the temperature of the electrode up to its melting. This is the fourth area of the CVC.

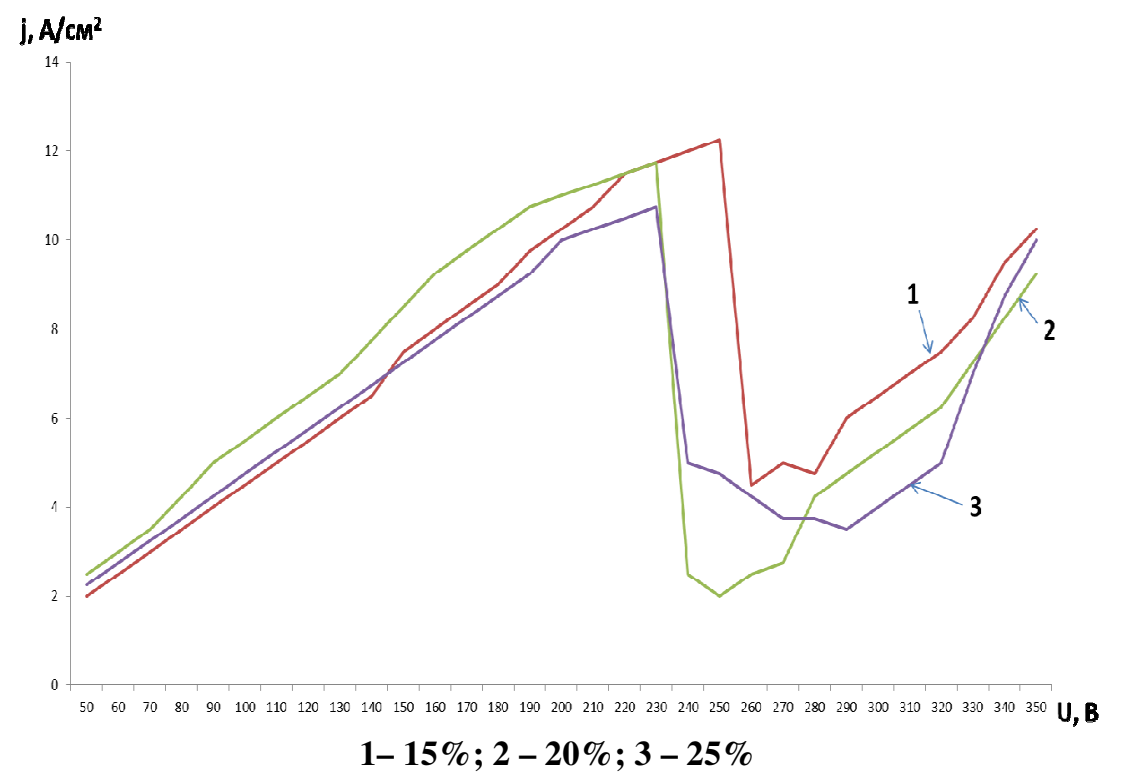

Figure 3: Current-voltage characteristics of the electrolytic cell (voltage increase) with an active cathode for electrolytes with different concentrations of urea

Figure 4 shows the CVC for urea-sodium electrolytes obtained by reducing the voltage. There is observed a shift of the above-described areas of the CVC toward lower voltages. The current is much higher at the same voltages in the CVCin many areas, compared with the CVC obtained by increasing the voltage. The length of the fourth and third areas is much larger, and the length of the first area is smaller. Moreover, sections are observed in the third area where the current remains constant and stable discharge burning is detected in these areas. All this is associated with heating of the active electrode at the beginning of the process due to high voltages, which leads to heating of the active electrode and electrolyte near the surface of the active electrode. So, the electrolyte temperature for all electrolytes was $30-35{ }^{\circ} \mathrm{Cat}$ the beginning of the process. In the process, it amounted to $50-60{ }^{\circ} \mathrm{C}$. Thus, favorable conditions appear for burning a stable discharge to relatively low voltagesdue to heating of the electrolyte. 


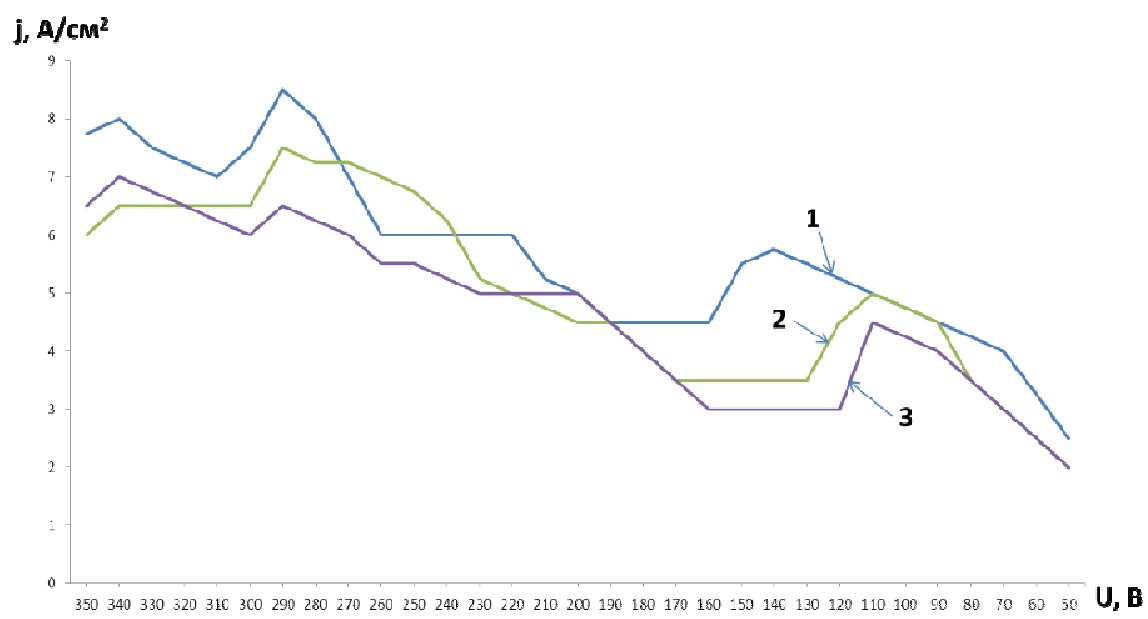

$1-15 \% ; 2-20 \% ; 3-25 \%$

Figure 4: Current-voltage characteristics of the electrolytic cell (to reduce voltage) with an active cathode for electrolytes with different concentrations of urea

Figure 5 shows the CVC for an electrolyte containing $20 \%$ urea and $10 \%$ sodium carbonate, obtained by increasing the voltage with a subsequent decrease. It was found that a decrease in voltage after the onset of the fourth stage - a stable abnormal discharge with a heated electrode, leads to hysteresis in the current-voltage characteristic of the electrolyte-plasma treatment process. In this case, with a subsequent decrease in voltage, the area of stable combustion of the anomalous discharge extends to significantly lower voltages (up to 250-260 V) than it was in the fourth stage in CVC for increasing voltage.

In this case, a gradual decrease in the temperature of the active electrode occurs. A decrease in current and the appearance of film boiling with the formation of a more stable low-temperature plasma (vapor-gas shell) are observed with a decrease in voltage to $260 \mathrm{~V}$, and it extends to a voltage of $120 \mathrm{~V}$. This is the third area of the CVC. Then there is a sharp increase in current and the occurrence of bubble boiling (second area). We again come to the first areawith a further decrease in voltage. However, due to heating of the electrolyte, its resistance changes, and the inverse branch of the characteristic does not coincide with the forward branch.

Thus, under a subsequent decrease in voltage, an increase in the length of the third and fourth areas and a decrease in the length of the first and second areas were detectedin the CVC. This is primarily due to the heating of the active electrode (cathode). So, the active electrode was heated to $400-500{ }^{\circ} \mathrm{C}$ due to an abnormal discharge when the CVC was obtained to increase the voltage (fourth area) at the end of the process and the active electrode undergoes the fourth area, and its heating continues until the third area at the beginning of the subsequent voltage reduction.

The active electrode cools very slowly due to film boiling in the third area, which leads to an increase in the length of the third area. The heated electrodewill heat the electrolyte near its surface. The thickness of the vapor-gas shell may decreasedue to the heating of the active electrode and the electrolyte, which gives a favorable condition for burning a stable discharge with a large length. At the same time, two areas of practical interest can be observed in the CVC: 1 area characterized by stable intense burning of an anomalous discharge and 2 area of a stable (glow-spark) discharge. 


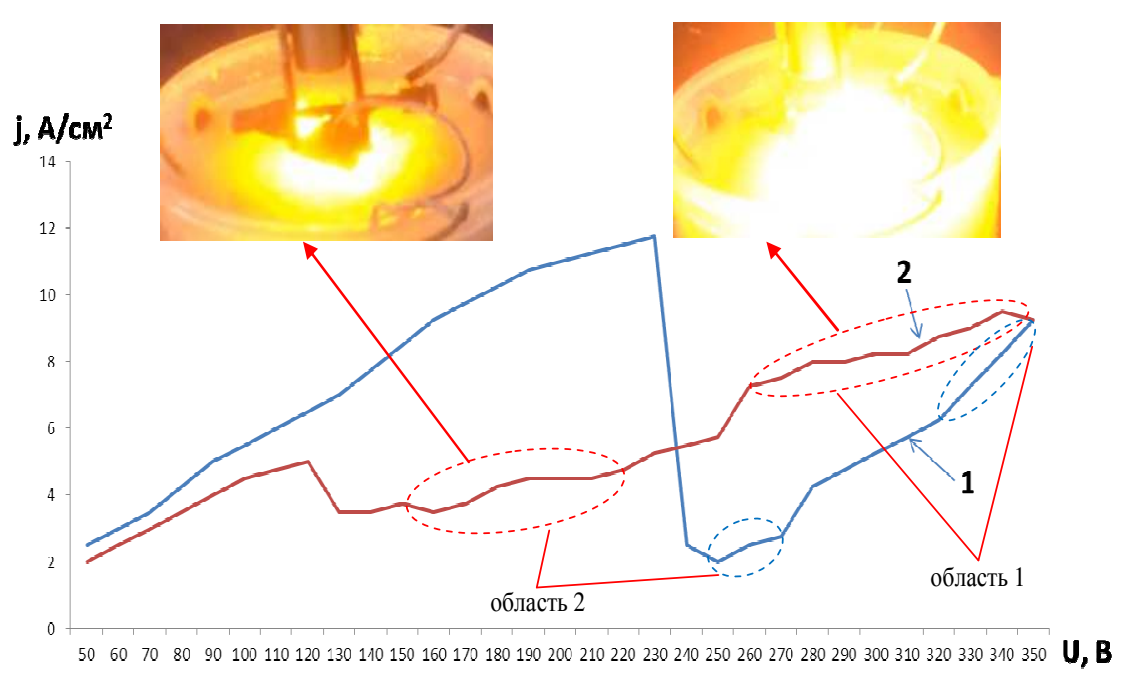

Figure 5: Current-voltage characteristics of an electrolytic cell with an active cathode for an electrolyte containing $20 \%$ urea and $10 \%$ sodium carbonate to increase (1) followed by a decrease (2) in voltage

We obtained the CVC of the cathodic heating process at various temperatures of the electrolyte and the active electrode (cathode) in order to establish the possibility of controlling the electrolyte-plasma discharge and establish the boundaries of the working areas for PES.

Figure 6 shows the CVC at electrolyte temperatures of $60,70,80$, and $90{ }^{\circ} \mathrm{C}$. It can be seen from the figure that the length of the first and second area - the are of normal electrolysis and the are of bubble boiling - decreaseswith an increase in the electrolyte temperature. And the length of the third and fourth area is increasing. In this case, the first and second areas do not differ in type of CVC; they can be detected by visual observation. It was found that with electrolytes heated to 70,80 , and $90^{\circ} \mathrm{C}$, the processes of the third area - film boiling processes are more stable and are characterized by a long duration.

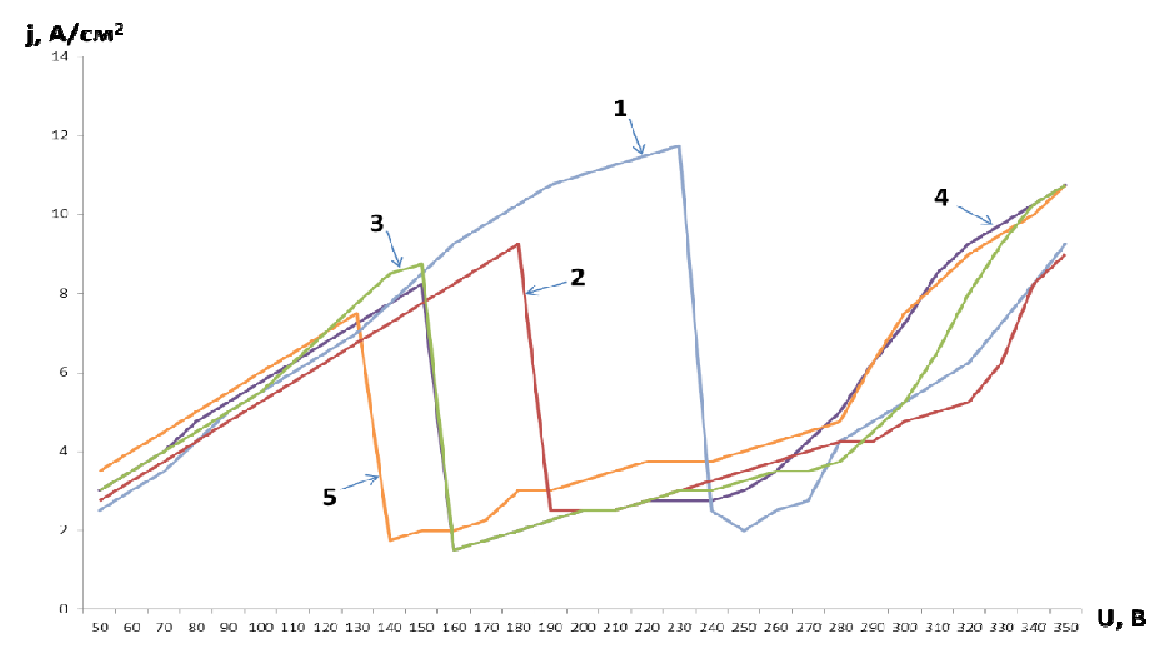

Electrolyte temperature: 1- 30 $\square \mathrm{C}$; 2- 60 $\square \mathrm{C}$; 3- 70 $\square \mathrm{C}$; 4- 80 $\square \mathrm{C}$; 5- 90 $\square \mathrm{C}$

Figure 6: Current-voltage characteristics of the electrolytic cell with an active cathode for preheated electrolytes containing $20 \%$ urea and $10 \%$ sodium carbonate

CVC obtained with a preheated active electrode (cathode) showed that the process is very similar to the process with a heated electrolyte (Figure 7). All four of the above areas are observed when the electrode is preheated to $300^{\circ} \mathrm{C}$, and only three areas are observed when the electrode is preheated to $500{ }^{\circ} \mathrm{C}$. In this case, the process begins with bubble boiling (second area). There is an increase in the length of the third area, which is necessary for the saturation process. 
It is known that the electrolyte-plasma process is stable at high voltage values (at 260 and $320 \mathrm{~V}$ ). In this case, deviations of the heating temperature and the difficulty of controlling the heating temperature are also not so significant, which leads up to the melting of the processed material. One can observe such areas in which a more stable discharge is observed at a voltage of 140-240 V from the obtained CVC for preheated electrolytes or a heated active electrode.Such stable discharges are not observed when the electrolyte or active electrode is not preheated. So, the process proceeds unstably and current surges occur under normal conditions at low voltage up to $240 \mathrm{~V}$. Thus, it becomes possible to obtain a stable discharge at lower temperatures by preheating the active electrode. Since obtaining a stable discharge at lower voltages is an urgent task from the point of view of energy conservation.

It is assumed that the observed stable discharges at lower voltages during preheating of electrolytes or an active electrode allow saturation of the surface of materials at lower temperatures (450-550), without affecting their roughness at low energy intensity. Since the energy-saving effect largely depends on the current density and is associated with the minimum allowable voltage during processing.

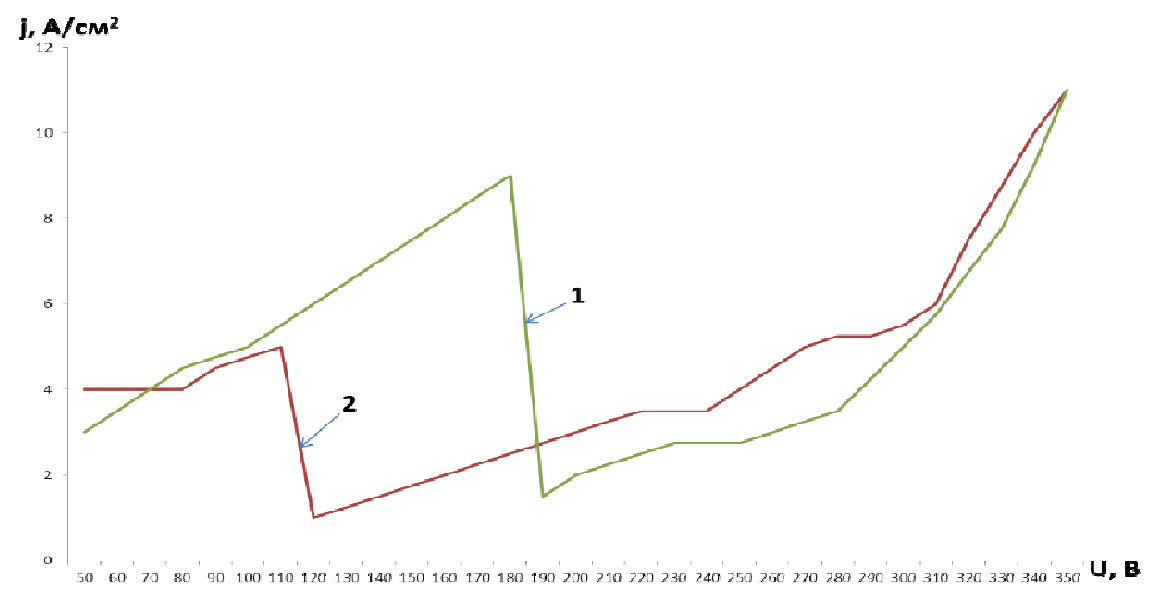

Active electrode temperature: 1 - $300{ }^{\circ} \mathrm{C} ; 2$ - $500 \square \mathrm{C}$.

Figure 7: Current-voltage characteristics of an electrolytic cell with an active cathode for a preheated active electrode (cathode)

Thus, the energy parameters of the process are determined on the basis of the studies, which made it possible to obtain a more stable, stable discharge. Nevertheless, it is necessary either that the electrolyte be heated from $70{ }^{\circ} \mathrm{C}$ or the active electrode (cathode) is heated to $500{ }^{\circ} \mathrm{C}$ to obtain a stable discharge at lower voltages. But this is time consuming and reduces the productivity of the processing process. In this regard, we have set the task of developing an effective regime of cathode electrolyte-plasma heating with high performance, which will allow the process of chemical-thermal treatment in a stable discharge.

A prerequisite is the existence of a stable vapor-gas shell (low-temperature plasma) around the processed material to obtain the chemicothermal treatmenteffect in an electrolyte plasma, which include active nitrogen ions, where penetrate deep into the surface of the material to form nitrided layers. The vapor-gas shell is formed and exists in a certain range of various parameters: electrical characteristics of the circuit, thermal conditions of film boiling, electrolyte properties, hydrodynamic conditions.

As it is known [20,21], the energy-saving effect largely depends on the material being processed and is associated with current density and voltageduring electrolyte-plasma treatment. It is possible to reduce the current density by adding surfactants to the electrolyte, which facilitate the conditions for the appearance of a vapor-gas shell. However, such 
additives during the cathodic process lead to instability of the vapor-gas shell, which does not allow the process to be carried out due to the difficulty of adjusting the cathode temperature. The vapor-gas shell is more stable at high voltage values of 260-320 V in the cathode mode. However, an intense glow of the vapor-gas shell with high-speed heating of the product is observed at such voltages, which complicates the temperature control process. All this is associated with the formation of an abnormal arc discharge in the contact of the cathode with the electrolyte. In addition, processing at high voltages increases the energy intensity of the treatment process. The processing process is unstable at lower voltages of 150-250 V.Current surges occur and in some cases it is impossible to heat the product. However, it was determined that at voltages of 170-220 V a stable vapor-gas shell can be obtained on the bases of conducted research in the previous section. In this case, either the electrolyte temperature should be higher and be $80-90{ }^{\circ} \mathrm{C}$, or the temperature of the active electrode is higher than $400{ }^{\circ} \mathrm{C}$.

Our experiments showed that a stable vapor-gas shell can be obtained at lower voltages of 170-220 V at an electrolyte temperature of $80-900{ }^{\circ} \mathrm{C}$ or at a cathode temperature above $400{ }^{\circ} \mathrm{C}$. However, the process of heating to a saturation temperature occurs slowly with a preheated electrolyte and it becomes difficult to keep the temperature at a certain level due to the relatively high temperature of the electrolyte when the saturation temperature is reached. In this case, it is necessary to quickly cool the electrolyte to the operating temperature $\left(50-70{ }^{\circ} \mathrm{C}\right)$ after reaching the saturation temperature. The temperature of the active electrode quickly reaches the saturation temperature in the process of processing a preheated active electrode (cathode) and there is no difficulty in keeping the temperature at a certain level. Thus, it becomes difficult to keep the temperature at a certain level, and according to the second embodiment when processing products according to the first embodiment, it will be necessary to preheat the active electrode to temperatures above $400^{\circ} \mathrm{C}$, which is a laborious process.

Table 1 shows the impact of voltage and temperature of the electrolyte on the stability of electrolyte-plasma heating process in the cathode mode. The experiments were carried out in an electrolyte from an aqueous solution containing $20 \%$ urea, $10 \%$ sodium carbonate.

It is seen from the analysis of table 1 that the process is unstable and current surges are observedwhen the temperature of the electrolyte and the active electrode (cathode) corresponds to room temperature during heating at a voltage of $200 \mathrm{~V}$, but the cathode is intensively heated until it melts at a voltage of $320 \mathrm{~V}$ the process is stable. Based on the table, it can be argued that in order to obtain a stable discharge it is necessary either to preheat the electrolyte or preheat the active electrode, which are not effective due to the complexity. The authors proposed a method of two-stage electrolyte-plasma heatingIn order to obtain a stable discharge without any additional operations.

Table 1: The impact of various heating conditions on the state of the process

\begin{tabular}{|c|c|c|c|l|}
\hline $\begin{array}{c}\text { Operating } \\
\text { voltage, } \mathbf{V}\end{array}$ & $\begin{array}{c}\text { Current } \\
\text { density, } \mathbf{A} / \mathbf{c m}^{\mathbf{2}}\end{array}$ & $\begin{array}{c}\text { Electrolyte } \\
\text { temperature, }{ }^{\circ} \mathbf{C}\end{array}$ & $\begin{array}{c}\text { Cathode } \\
\text { temperature, }{ }^{\circ} \mathbf{C}\end{array}$ & \multicolumn{1}{|c|}{ Process stability } \\
\hline 200 & $2-3$ & $20-30$ & $20-30$ & Unstable, inrush current \\
\hline 200 & $2-3$ & 60 & $20-30$ & Unstable \\
\hline 200 & $2-3$ & 80 & $20-30$ & Stable \\
\hline 320 & $6-7$ & $20-30$ & $20-30$ & Stable, intensive \\
\hline 200 & $2-3$ & $20-30$ & $200-220$ & Unstable \\
\hline 200 & $2-3$ & $20-30$ & $300-220$ & Unstable \\
\hline 200 & $2-3$ & $20-30$ & $400-420$ & Stable \\
\hline
\end{tabular}


The method of two-stage electrolyte-plasma heating is the heating of the active electrode (cathode) to $400-500^{0} \mathrm{C}$ with an abnormal discharge at voltages of 300-320 V, followed by a transition to the film boiling mode by a sharp decrease in voltage to $180-200 \mathrm{~V}$. Scheme of the process of electrolyte-plasma heating of the material in the two-stage mode is shown in Figure 8. The developed mode allows you to get a stable discharge without the use of any additional operations on the same installation, which reduces the complexity of the process while increasing the productivity of the process.

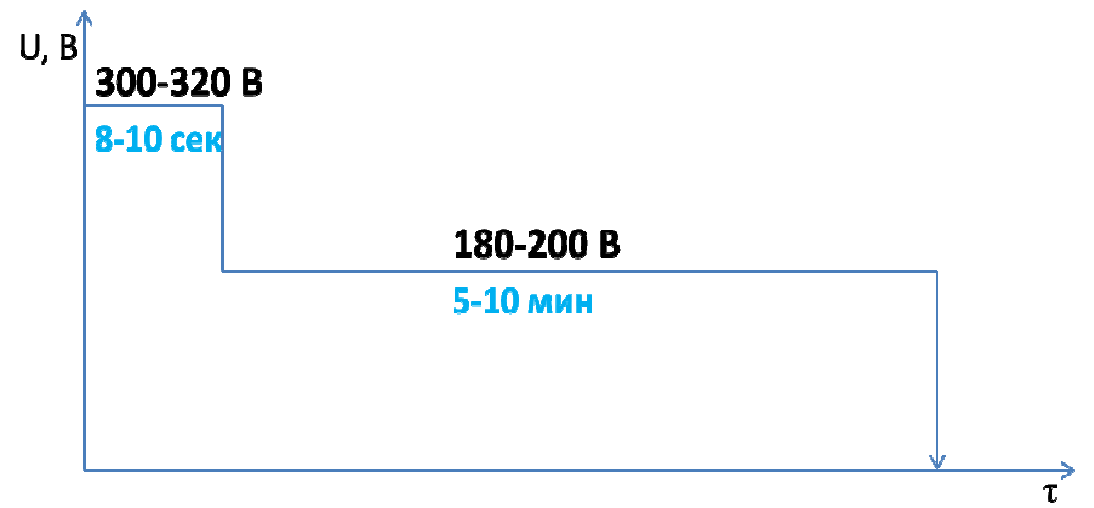

Figure 8: Scheme of electrolyte-plasma heating process of the material in a two-stage mode

The temperature of the active electrode quickly reaches the saturation temperature when heating in the developed two-stage mode when applying a voltage of 300-320 V and a subsequent decrease in voltage to 180-200 V allows you to keep the temperature at a certain level. Saturation temperature control can also be done by changing the electrolyte feed rate.

A higher voltage is used when two-stage electrolyte-plasma heating of the product at the first stage of processing and at the second stage lower. The first stage is used to heat the sample to a temperature above $200{ }^{\circ} \mathrm{C}$ and obtain a stable vapor-gas shell. The second stage is used to saturate the surface with nitrogen in an electrolyte plasma by keeping the cathode temperature at a certain level. The developed regime of two-stage electrolyte-plasma heating allows maintaining stable combustion of low-temperature plasma, provides smooth temperature control and eliminates the formation of an abnormal arc discharge during saturation, which worsens the surface roughness of the part.

A method of electrolyte-plasma nitriding of high-speed steels is developed on the bases of the developed regime of two-stage electrolyte-plasma heating. The developed method for nitriding high-speed steels is as follows. The working bath is filled with electrolyte before starting work. Then, the electrolyte with using a pump enters the electrolytic cellmounted on the bottom of the working bath. In this case, the electrolyte exits through the hole of the conical septum in the form of a jet and fills the electrolytic cell. Then the electrolyte is drained through the holes of the electrolytic cell, designed to drain the electrolyte, into the panand then back into the working bath.Thus, the electrolyte is in a circulating mode. The feed rate of electrolyte 2 (flow rate) is $4-71 / \mathrm{min}$. The flow rate of cooling running water to the heat exchanger is 3-6 1/min. The adopted electrolyte cooling parameters make it possible to maintain the electrolyte temperature in the range of $40-70{ }^{\circ} \mathrm{C}$ while heating the samples to a temperature of $500-600{ }^{\circ} \mathrm{C}$. The treatment workpiece with using the device for fastening is immersed in the electrolyte so that the treated zone of the products is $2-3 \mathrm{~mm}$ from the opening of the conical partition.In this case, an electrolyte stream is supplied to the treated zone through the hole of the conical septum, which is 10-15 mm lower than the height of the electrolytic cell. Then the anode is connected to the positive pole of the power source, and the workpiece - the cathode to its negative pole. A voltage of 260-320 V is applied between the electrodes and the current density is $3-4 \mathrm{~A} / \mathrm{cm}^{2}$ to heat to the saturation temperature.At such voltages, an intensely luminous plasma layer 
is formed in the cathode region, and the product heats up at a speed of $60-100{ }^{\circ} \mathrm{C} / \mathrm{s}$. In this case, an abnormal arc discharge is formed between the electrodes, due to which the processed tool quickly heats up [23]. A sharp decrease in voltage to 110-200 V initiates the transition of an abnormal arc discharge into a glow-spark discharge after reaching the saturation temperature (after 5-8 seconds).

In this case, a stable vapor-gas layer (vapor-gas shell) is formed in the cathode region, due to which the temperature is maintained at a certain level. If necessary, the temperature is also controlled by a change in the pressure of the electrolyte. This mode of two-stage heatingdoes not allow the tool to be eroded by a strong increase in roughness, and also provides the ability to control the heating temperature of the processed cathode tool, and, therefore, the diffusion saturation process, that it allows you to smoothly control and maintain the temperature at a certain level. The magnitude of the secondary voltage in turn depends on the composition of the electrolyte and on the ratio of the area of the anode to the cathode.

\section{CONCLUSIONS}

The energy parameters of the process are determined on the bases conducted research, which made it possible to obtain a more stable discharge. It was revealed that it is necessary either that the electrolyte be heated from $70{ }^{\circ} \mathrm{C}$ or the active electrode (cathode) is heated to $500{ }^{\circ} \mathrm{Cin}$ order to obtain a stable discharge at lower voltages. The authors have developed an efficient two-stage cathodic heating mode in order to obtain a stable discharge, which allows for controlled cathodic plasma electrolytic saturation (PES) of steels.The method of two-stage electrolyte-plasma heating is the heating of the active electrode (cathode) to $400-500^{\circ} \mathrm{C}$ with an abnormal discharge at voltages of $300-320 \mathrm{~V}$, followed by a transition to film boiling mode by a sharp decrease in voltage to $180-200 \mathrm{~V}$. The developed mode allows to obtain a stable discharge without using any additional operations on the same installation, which reduces the complexity of the process while increasing the productivity of the process.

Thus, the developed two-stage heating mode makes it possible to use the cathodic process of electrolyte-plasma heating for plasma electrolytic saturation (PES) of products and at not high temperatures, which allows you to use this method as a finish of products, in particular, to nitrate cutting tools made of high-speed steels passed hardening heat treatment. This mode also allows you to automate the PES process.

\section{ACKNOWLEDGMENT}

The work was performed in the framework of program-targeted funding of the Committee of Science of the Ministry of Education and Science of the Republic of Kazakhstan for 2018-2020 (BR 05236748).

\section{REFERENCES}

1. Gupta P., Tenhundfeld G., Daigle E.O., Ryabkov D. (2007). Electrolytic plasma technology: Science and engineering - an overview // Surf. \&Coat. Technol., 25, 87-96.

2. B.K. Rakhadilov, Z.A. Satbayeva, L.B. Bayatanova, M.K. Kilyshkanov, K.A. Kalibayev, A.K. Kochneva (2019). Influence of Electrolyte-Plasma Surface Hardening on the Structure and Properties of Steel 40HN // Journal of Physics: Conference Series, 1393, 012119.

3. HusseinR.O., Nie X., Northwood D.O., Yerokhin A., Matthews A.(2010). Spectroscopic study of electrolytic plasma and discharging behaviour during the plasma electrolytic oxidation (PEO) process // Journal of Physics D: Applied Physics, 43(10), 105203. 
4. Belkin P.N., Naumov A., Shadrin S., Dyakov I.G., Zhirov A., Kusmanov S.A., Mukhacheva T. (2013). Anodic Plasma Electrolytic Saturation of Steels by Carbon and Nitrogen // Advanced Materials Research. - Vol. 704, 37-42.

5. Zhurerova L.G., Rakhadilov B.K., Popova N.A., Kylyshkanov M.K., Buranich V.V., Pogrebnjak A.D. (2019). Effect of the PEN/C surface layer modification on the microstructure, mechanical and tribological properties of the 30CrMnSiA mildcarbon steel /Journal of Materials Research and Technology, 78-85.

6. J. Pang, W. Lu, W. Liu, S. Zhang, Y. Sun, D. Zuo (2018).Diffusion of carbon and nitrogen in TC4 titanium alloy plasma electrolytic saturation / Chem. Phys. 505, 12-18.

7. P.N. Belkin, I.V. Tambovskiy, S.S. Korableva, S.A. Silkin, S.A. Kusmanov (2018).Anodic plasma electrolytic nitrocarburizing of VT22 titanium alloy in carbamide electrolyte / J. Surf. Investig. 12 (3), 507-512.

8. C.K. Levent, O. Ahmet (2013).Plasma electrolytic saturation of 316 L stainless steel in an aqueous electrolyte containing urea and ammonium nitrate / Mater. Technol. 47 (3), 307-310.

9. Z. Li, Y. Cheng, S.H. Kang, W. Tu, Y. Cheng (2018) A re-understanding of the breakdown theory from the study of the plasma electrolytic oxidation of a carbon steel - Anon-valve metal / Electrochim. Acta 284, 681-695.

10. Y. Chen, X. Song, J. Zhou, H. Liu, Y. Yang(2018). The study on the overall plasma electrolytic oxidation for 6061-7075 dissimilar aluminum alloy welded parts based on the dielectric breakdown theory / Materials 11 (1) Art. no. 63.

11. Belkin, V. S., Belkin, P. N., Krit, B. L., Morozova, N. V., \& Silkin, S. A. (2019). Increasing Wear Resistance of Low-Carbon Steel by Anodic Plasma-Electrolytic Nitroboriding / Journal of Materials Engineering and Performance. 29, 564-572

12. S.A. Kusmanov, A.A. Smirnov, S.A. Silkin, and P.N. Belkin (2016). Modification of Low-Alloy Steel Surface by Plasma Electrolytic Nitriding / J. Mater. Eng. Perform., 25(7), 2576-2582

13. H. Tavakoli, S.M. Mousavikhoie, F. Rasooli, S.P.H. Marashi, and F. Momeni (2015). Electrochemical and Physical Characteristics of the Steel Treated by Plasma-Electrolysis Boronizing / Surf. Coat. Technol., 276, 529-533

14. Dyakov, I. G., Burov, S. V., Belkin, P. N., Rozanov, E. V., \& Zhukov, S. A. (2019). Increasing wear and corrosion resistance of tool steel by anodic plasma electrolytic nitriding /Surface and Coatings Technology, 362, 124-131.

15. P. Taheri, C. Dehghanian, M. Aliofkhazraei, and A.S. Rouhaghdam (2007). Nanocrystalline Structure Produced by Complex Surface Treatments: Plasma Electrolytic Nitrocarburizing, Boronitriding, Borocarburizing, and Borocarbonitriding / Plasma Process. Polym., 4, 721-727.

16. Kim Sung Wan., Kim Sang Gweon., Moon Kyoung Il., Cho Yong Ki.//KR 100661130* - Method for nitriding stainless steel by post-plasma, capable of securing high nitriding characteristics and surface roughness by increasing temperature uniformity and nitriding ion density within a furnacel/ Korea Institute of Industrial Technology.

17. Rakhadilov B.K., Skakov M.K.,Scheffler M. (2015). Microstructure and Tribological Properties of Electrolyte Plasma Nitrided High Speed Steel //Materials testing, № 4(57),360-365

18. Reiser Yu.P. (1972). The distribution of discharges and the maintenance of a dense plasma by electromagnetic fields // Uspekhi Fizicheskikh Nauk - T. 108. - Issue. 3, 429-461.

19. Mukhacheva T.L. Dyakov I.G. (2007). Anodic saturation of steels with nitrogen and carbon/Electrochemical and electrolyteplasma methods for the modification of metal surfaces: Mat. II international scientific. - tech. conf. - Kostroma: N.A. Nekrasov $K S U, 215-217$.

20. KulikovI.S., VashchenkoS.V., KamenevA.Ya. (2010). Electrolyte-plasma processing of materials // NAS of Belarus, Joint Institute for Energy Research - Pines. - Minsk: Belarusnavuka. 
21. Suminov I.V., Belkin P.N., Epelfeld A.V. et al. (2011). Plasma-electrolytic surface modification of metals and alloys / ed. I.V. Suminova; in 2 volumes - M: Technosphere, - T.1.

22. Popilov L.Ya. (1982). Electrophysical and electrochemical processing of materials: a reference book. - M.: Mechanical Engineering. 